\title{
Letter to the Editor concerning "Handgrip strength correlates with walking in lumbar spinal stenosis" by Inoue H. et al. [Eur Spine J (2020): DOI 10.1007/s00586-020-06525-1]
}

\author{
Kalyan Kumar Varma Kalidindi ${ }^{1}$ (D . Jeevan Kumar Sharma ${ }^{1}$
}

Received: 6 August 2020 / Revised: 6 August 2020 / Accepted: 24 August 2020 / Published online: 2 September 2020

(c) Springer-Verlag GmbH Germany, part of Springer Nature 2020

To the Editor,

We read with great interest an article titled "Handgrip strength correlates with walking in lumbar spinal stenosis" authored by Inoue et al. [1]. They examined the relationship between handgrip strength and leg extension power, walking speed, and intermittent claudication for lumbar spinal stenosis (LSS). They concluded that the more handgrip strength patients with LSS have, the more LEP, the faster walking speed, the greater area of psoas muscle, the fewer steps for a 10-m walk, and the longer intermittent claudication they have. We would like to congratulate the authors for their commendable work in conducting the study. However, we have a few concerns for which we seek clarification.

1. For a patient who presents to us with a weak handgrip, we would evaluate for the common causes such as carpal tunnel syndrome, peripheral neuropathy, or joint arthritis [2-4]. We were surprised to see that such conditions were not included in the selection criteria for patients. Also, we also noticed that investigations such as a nerve conduction study were not performed to evaluate the reason for poor handgrip function in your patients. Such conditions in your study population may grossly influence the results of the study.

2. The authors observed that the handgrip strength correlated with factors such as gender, age, height, weight, and comorbidities such as anemia and hypertension. However, they concluded that in lumbar spinal stenosis patients, handgrip strength indicates not only a parameter of whole body muscle strength but also walking abil-

Kalyan Kumar Varma Kalidindi

kalyan_varma_mbbs@yahoo.com;

kalyanvarmambbs@gmail.com

1 Department of Spine Service, Indian Spinal Injuries Centre, Vasant Kunj, New Delhi, India 110070 ity. It is possible that if the factors such as age, weight, or comorbidities are confounders and, if removed, can change the outcomes by a clinically significant amount. How did the authors exclude the possibility of a spurious association?

Once again, we compliment the authors for their work and hope that the readers may benefit from it.

\section{Compliance with ethical standards}

Conflict of interest None.

\section{References}

1. Inoue $\mathrm{H}$, Watanabe $\mathrm{H}$, Okami $\mathrm{H}$ et al (2020) Handgrip strength correlates with walking in lumbar spinal stenosis. Eur Spine J. https://doi.org/10.1007/s00586-020-06525-1

2. Baker NA, Moehling KK, Desai AR, Gustafson NP (2013) Effect of carpal tunnel syndrome on grip and pinch strength compared with sex- and age-matched normative data. Arthritis Care Res (Hoboken) 65(12):2041-2045. https://doi.org/10.1002/acr.22089

3. Lima KCA, Borges LDS, Hatanaka E, Rolim LC, de Freitas PB (2017) Grip force control and hand dexterity are impaired in individuals with diabetic peripheral neuropathy. Neurosci Lett 659:54-59. https://doi.org/10.1016/j.neulet.2017.08.071

4. Higgins SC, Adams J, Hughes R (2018) Measuring hand grip strength in rheumatoid arthritis. Rheumatol Int 38(5):707-714. https://doi.org/10.1007/s00296-018-4024-2

Publisher's Note Springer Nature remains neutral with regard to jurisdictional claims in published maps and institutional affiliations. 